\title{
El mito como elemento transgresor en la novela postmoderna: Truismes de Marie Darrieussecq
}

\author{
Ángeles SÁNCHEZ HERNÁNDEZ \\ Universidad de Las Palmas de Gran Canaria \\ asanchez@dfm.ulpgc.es
}

Recibido: $10 / 06 / 2012$

Aceptado: 23/01/2013

\section{Resumen}

Este artículo analiza una novela publicada en los últimos años del siglo XX, Truismes de M. Darrieussecq (1996), cuya desarrollo recoge algunas técnicas narrativas que han marcado la novela posmoderna. El mito de la metamorfosis sirve a la escritora para mostrar y deconstruir una serie de clichés del imaginario colectivo aplicados a la mujer en la sociedad occidental. En tono humorístico, se abordan cuestiones relativas a la formación de la identidad y la integración social, de absoluta vigencia en el siglo XXI.

Palabras clave: mito, mujer, literatura postmoderna, autoficción.

\section{Le mythe comme élément transgresseur dans le roman postmoderne : Truis- mes de Marie Darrieussecq}

\begin{abstract}
Résumé
Dans cet article, nous étudions un roman publié dans les dernières années du $\mathrm{XX}^{\mathrm{e}}$ siècle qui a marqué le roman postmoderne. Le mythe de la métamorphose permet à l'auteur de montrer et déconstruire toute une série de clichés de l'imaginaire collectif liés à la femme dans la société occidentale. Sous un ton humoristique, on aborde des thèmes relatifs à la formation identitaire et à l'intégration sociale qui restent encore des sujets clés à l'heure actuelle.
\end{abstract}

Mots clés: mythe, femme, littérature postmoderne, autofiction.

\section{The myth as an element of transgression in the postmodern novel: Truismes by Marie Darrieussecq}

\begin{abstract}
This paper is a study of a novel published in the final years of the twentieth century entitled Truismes by Marie Darrieussecq (1996). It makes use of some narrative techniques characteristic of the postmodern novel. Through the myth of the metamorphosis the author reveals and deconstructs a series of clichés from the collective imaginary, and applied to women in Western societies. With a humorous tone, the subject matter addresses real issues also under debate in the twenty-first century, such as identity and social integration.
\end{abstract}

Keywords: myth, women, postmodern literature, autofiction. 
Referencia normalizada

Sánchez Hernández, Á. (2013). "El mito como elemento transgresor en la novela postmoderna: Truismes de Marie Darrieussecq". Thélème, Vol. 28, 243-257.

Sumario: 0. Introducción. 1. Mito y transgresión en la literatura postmoderna. 2. Cuerpo, identidad e inserción social en Truismes. 3. Conclusión.

\section{Introducción}

En este artículo analizaremos una de las novelas francesas de los últimos años del siglo XX que ha disfrutado de un éxito importante, Truismes (1996) de Marie Darrieussecq, cuya publicación supuso un revulsivo para la sociedad francesa de aquel momento. El periodo de elaboración de esta obra coincide con la redacción de su tesis doctoral. El dato resulta útil porque ofrece alguna pista sobre las técnicas narrativas que conoce en profundidad; entre ellas, dedica especial atención a la llamada autoficción en la que centra el análisis de su doctorado ${ }^{1}$. La novela que nos ocupa está narrada desde la primera persona de la protagonista, la femme-truie.

La utilización del mito ancestral de la transformación del hombre en animal facilita las claves de algunas nociones de la narración postmoderna en Francia, en particular aquella escrita por mujeres. La tipología mítica del personaje principal, la femme-truie, permite a Darrieussecq distanciarse de la realidad para relatar y analizar en clave de humor una problemática que le concierne íntimamente. El mito le proporciona una penetración multiforme del mundo para analizar el papel de la mujer en el contexto social contemporáneo y para elaborar su relato desde una nueva perspectiva, una forma innovadora capaz de relatar la realidad multiforme actual. La escritora afirma: "Je cherche à inventer de nouvelles formes, à écrire de nouvelles phrases, parce que c'est le seul moyen de rendre compte du monde moderne" (Miller \& Holmes, 2001). Este relato constituye una forma de cuento moral, entre fábula feminista y sátira social.

El título lleva ya inscrito la articulación deconstructiva que la novela comporta, como ha subrayado Pierre Brunel (2002a: 147): "Le jeu de mots fondateur truie/truisme est bien un jeu de déconstruction". Ese juego deconstructivo alude a la ambivalencia significativa que posee la palabra en francés, por un lado se refiere a la hembra del cerdo, animal en el que se convierte la protagonista y, por otro, indica una verdad tan evidente que no necesita mencionarse. A la vez, en una recreación

\footnotetext{
${ }^{1}$ Titulada Moments critiques dans l'autobiographie contemporaine: l'ironie tragique chez Serge Doubrovsky, Hervé Guibert, Michel Leiris et Georges Perec, 1997. Tesis inédita, algunas de sus claves aparecen en su artículo "L'autofiction, un genre pas sérieux" en la revista Poétique. №107, pp. 369-380.
} 
intertextual, se nos citan los Tropismes de Sarraute como marca de lo que se ha denominado platitude verbale (Brunel, 2002b: 189). Esta línea minimalista de escritura, en apariencia simple, emerge en otras novelistas contemporáneas para ser reivindicada con fuerza como rasgo diferenciador de su narrativa. A este propósito, recordemos la obra de Annie Ernaux, aunque hay que observar que la écriture plate de esta última está alejada de toda fabulación humorística o fantástica, pero ambas escritoras comparten la dimensión sociológica de su escritura.

La carencia de recursos lingüísticos que presenta la protagonista se corresponde con la falta de formación intelectual que le impide explicar, y explicarse a sí misma, los fenómenos que ocurren a su alrededor y en su propio cuerpo. Precisamente, las trasformaciones físicas le obligan a estructurar su pensamiento buscando las palabras capaces de expresar las mutaciones que se producen en su cuerpo, esta necesaria construcción del discurso para comunicarse organiza su mente simultáneamente. La pobreza lingǘstica o la simplicidad estructural que los personajes presentan suponen una elección narrativa que trata de exponer situaciones cotidianas en un relato que se distancia así del modelo de escritura convencional. La banalidad de sus frases constituye el símil de los acontecimientos ordinarios que vive la protagonista, esa trivialidad inscrita en el título. Emplea esta técnica para marcar la pauta de cuento ligero y fantástico que parece no contener más interés que el mero divertimento, pero que se arraiga, sin embargo, en un sentimiento feminista frente a las exigencias sociales reclamadas a la mujer habitualmente.

Al gestar esta novela, Darrieussecq se preguntó cuál sería el peor insulto que podría dirigirse a una mujer, para ella estaba claro que la palabra truie adquiría un impacto mayor por sus numerosas connotaciones. El término francés alude a una mujer de mala reputación y de costumbres poco saludables, según el canon social considerado como normativo. Este aspecto relacionado con su sexo resultó decisivo para convertir a la mujer protagonista de la novela en cerda. El personaje carece incluso de nombre, una de las señas de identidad mayores del ser humano, como signo de la intensa despersonalización que padece. Esta mujer no posee rasgos de identidad estables ni referentes que guíen su experiencia vital.

Bajo la aparente sencillez narrativa de la historia, el lector descubre el mundo en el que la protagonista está obligada a vivir, reflejado narrativamente mediante un universo de ficción insólito. Tras una primera mutación de mujer en cerda, el personaje atraviesa una fluctuación en ese cambio de forma corporal como consecuencia de la inestabilidad en su identidad. Este personaje, desde la inconsciencia inicial en la que vive, acepta las normas del hombre de quien depende, Honoré, de manera sumisa. La femme-truie vive presionada por influencias sociales que la dominan, ejecuta de forma irreflexiva sus dictados, supera sentimientos de frustración y soledad hasta llegar al desenlace final, momento en el que logra un cierto control sobre su vida. En este epílogo, ambos lados de su personalidad, el racional y el animal, terminan por asociarse para coexistir de forma consciente.

En la literatura clásica la transformación en animal respondía generalmente a algún efecto mágico; sin embargo, en Truismes no intervienen elementos externos en la transformación. Las trasformaciones de la joven no provienen de una causa 
objetiva sino que responden a alteraciones emocionales de tal magnitud que el cuerpo registra los cambios metamorfoseándose. El mundo inconsciente se apodera de la parte material del ser como prueba irrefutable de una realidad existencial en esta mujer: cuerpo y espíritu son indisolubles y se manifiestan al unísono. La mutación vacilante de la protagonista de Truismes no es frecuente ya que, tradicionalmente, la metamorfosis de hombre en animal constituye un proceso irreversible como sucede a cualquier animal durante su desarrollo evolutivo hasta convertirse en adulto, con la consiguiente variación fisiológica y comportamental. La escritora ha apuntado la influencia de la obra de Orwell en la que se presenta la sociedad totalitaria a través de los animales y, asimismo, reconoce el influjo de Kafka sobre su novela, pero ella quiere marcar, además, la estrecha relación entre la mujer, su fisiología y la influencia de la sociedad, dibujando un desarrollo paulatino de la personalidad y la reafirmación final de su entidad, que no responde a los cánones habituales de corrección social.

\section{Mito y transgresión en la literatura postmoderna francesa}

Comenzaremos explicando las dos voces que introducen este apartado: mito y literatura postmoderna. El mito de la metamorfosis es un tema con raíces muy antiguas en nuestra cultura. Presente ya en Homero y el Ciclo Épico, alcanza su mayor desarrollo en época helenística y su culminación en las Metamorfosis de Ovidio, obra que se convirtió en el principal transmisor de este tema a la cultura moderna. Pero la metamorfosis no es solo un motivo artístico y literario, sino que tiene también un componente filosófico y religioso, por su relación con el concepto órfico-pitagórico de la transmigración de las almas (metempscosis) y establece además una relación - en un plano metafórico- con los presupuestos del materialismo antiguo. Cuando decimos, en efecto, que Filomela se convierte en ruiseñor o Hécuba en perra, que Hermafrodito se asimila a las aguas del estanque en el que se arroja, que Níobe se convierte en piedra, estamos diciendo, en realidad, que abandonan su existencia humana para adquirir otra forma de vida, o mejor, de pervivencia, de acuerdo con el principio bien conocido de que nada se pierde, sino que todo se transforma (Martín Rodríguez, 2002: 256-260). La idea de la transmutación de especies estaba ya en germen en el pensamiento francés del siglo XVIII; para Diderot, en su obra Le rêve de d'Alembert, todos los seres circulan los unos en los otros $\mathrm{y}$, consecuentemente, se establece entre todas las especies un flujo perpetuo. La abolición de las fronteras entre las distintas especies desembocaría en una metamorfosis generalizada (Brunel, 2004: 57).

El término de 'postmodernidad' se emplea con frecuencia en buena parte de los estudios consagrados a la literatura del siglo XX (Sarrey-Strack, 2002: 25). Creemos conveniente, pues, recurrir a esta denominación para unificar perspectivas dentro de la evolución de la novela occidental contemporánea, a pesar de las controversias que ha suscitado esta expresión en Francia donde existe cierta resistencia a su utilización, muy al contrario de lo que ocurre en el ámbito anglosajón. Al 
pensar en la literatura francesa del último cuarto del siglo XX, coincidimos con Petr Dytrt (2009: 80) cuando señala que es casi imposible ignorar esta noción dada su relevancia en el terreno intelectual y artístico en el citado periodo. En Francia, las tesis de la postmodernidad comienzan a plantearse hacia 1983, momento en el que la revista Tel Quel se convierte en L'Infini y los padres del Nouveau roman, los llamados autores "modernos", producen obras que derivan hacia la autobiografía o la autoficción. La definición que ofrece Le Dictionnaire du littéraire de esta tendencia es la siguiente:

Le postmodernisme culturel présente, [...], deux tendances principales selon Bertens : la réintroduction de représentation et du narratif, mais aussi une " autoréflexivité anti-représentationnelle », le facteur commun étant une crise de la représentation, un manque de foi en la capacité de représenter le réel. En littérature cela donne lieu à une littérature de «l'épuisement » ou du « renouvellement» (Barth), caractérisée par la combinaison paradoxale de l'autotextualité et de la référence historique [...], par le recyclage et la subversion des conventions $[\ldots]$; et par l'essor des voix marginalisées [...]. D'autres traits des œuvres postmodernes comprennent l'hybridité (générique ou autre), une intertextualité très poussée, la parodie, des jeux temporels, un accent sur la multiplicité des petits récits et la déconstruction des oppositions binaires rigides (Aron, 2002: 378).

Pierre Brunel ${ }^{2}$ considera también que este movimiento recupera los referentes culturales occidentales tras 1980 y renueva la tradición literaria. Según el filósofo François Lyotard, uno de los precursores del concepto, la postmodernidad consiste en una relectura o anamnèse de la modernidad. Esta revisión del pasado no solo se lleva a cabo en el ámbito filosófico sino también en otras esferas culturales, lo que conlleva una nueva forma de autoanálisis filosófico y estético (Brügger et al., 1993: $30)$.

A diferencia de la tendencia americana, la corriente europea no rechaza esa renovación novelística que supuso el nouveau roman sino que lo revisa para someterlo a una relectura crítica reagrupando sus elementos para crear así un paradigma nuevo (Dytrt, 2009: 81). Una práctica literaria se considera postmoderna cuando pone en duda, tanto en el plano formal como en el plano del contenido, las nociones de unidad, de homogeneidad y de harmonía. Algunos estudios, como el realizado por la investigadora Janet Paterson sobre un corpus de novelas canadienses, señalan como técnicas más usuales de los escritores de este movimiento: "l'intertextualité, la représentation de l'écrivain dans la fiction et la remise en question de l'Histoire" (Sarrey-Strack, 2002: 28).

Estas estrategias narrativas tratarían de confundir los códigos existentes en los diferentes niveles textuales, buscando con ello nuevas formas de expresión que descubran un nuevo sentido al texto. Los principios de los llamados nouveaux romanciers han dejado su huella en la generación posterior. Ciertos escritores de finales del siglo XX revisan los criterios narrativos de la generación anterior e

\footnotetext{
${ }^{2}$ Citado en Dytrt (2009: 82).
} 
integran algunos de sus recursos en las novelas con métodos distintos, engendrando otros modelos de historias. El lenguaje, preocupación mayor de la generación de Tel Quel, constituye un centro de interés substancial en Truismes.

A través del empleo del mito con todas sus referencias literarias tradicionales, la protagonista-narradora examina su identidad, acercándonos a la creación conocida como autoficción; ese interés por las existencias individuales en un preciso entorno social es una característica clave de la actual novelística (Viart \& Vercier, 2008: 7). La escritora crea una historia imaginaria en la que construye un personaje a su medida, a la medida de las inquietudes de una mujer que trata de encontrar su identidad en la sociedad de finales del siglo XX. Darrieussecq ha hablado en varias ocasiones a propósito de esta forma de creación literaria y, al referirse a ella, afirma que no se trata únicamente de una vida fictionnalisée, sino que se trata de una metamorfosis completa de la vida.

En una conferencia pronunciada en Roma bajo el título: "Je est une autre", feminizando la frase de Rimbaud, explica su visón del género inaugurado por Douvrovsky afirmando:

La dimension du fantasme, comme jeu ou distorsion de l'identité, est très présente dans l'écriture de Cendrars, jusqu'à côtoyer les frontières de la folie. L'autofiction décalque sur le papier le jeu, ou le trouble, psychique. Dans le fantasme, y compris le fantasme sexuel, le sujet se met en scène dans des situations fictives, qu'il ne souhaite pas nécessairement vivre, mais qu'il expérimente mentalement. Pour moi l'autofiction c'est ça : un fantasme filé sur la page, sous mon nom, dans ma peau, mais une peau de papier, une peau mentale (Darrieussecq, 2007).

Los personajes novelescos de Darrieussecq poseen cierta carga de irrealidad, ya sea bajo forma de mujer-animal o de fantasma en publicaciones posteriores. Esta práctica le ofrece la oportunidad de estudiar de forma distanciada el malestar psíquico de la protagonista y de deconstruir los estereotipos sociales de la mujer. La insatisfacción anímica en la que sobrevive el personaje - sin ser consciente de ella - va a originar los cambios físicos para adaptarse al medio social y a las expectativas que despierta en su entorno; esos primeros cambios traducen su vida como prostituta.

La escritora utiliza el mito greco-latino de la metamorfosis, pero maneja recursos psicoanalíticos para completar su creación narrativa e instaura un análisis sociológico recurriendo a otras ciencias humanas para elaborar su discurso literario, otro rasgo particular de la literatura francesa contemporánea. El personaje de la truie con sus cambios de mujer a animal permite mostrar la indisolubilidad de cuerpo y mente en la existencia humana, en mayor medida aún en la vida femenina ya que la mujer está sujeta a cambios fisiológicos cíclicos que condicionan la unión de las dos vertientes del ser humano, cuerpo y espíritu, más aún que en el hombre. El factor biológico aleja el comportamiento de esta mujer de la conducta normativa en la cultura occidental en la que prima la razón como guía del comportamiento humano. La profesora Silvia Tubert (1996) asegura que: "Tanto el psicoanálisis como el posmodernismo y el feminismo han descentrado la concepción ilustrada de un sujeto unitario esencialmente racional". La protagonista vive su vida de forma 
alienada, las mutaciones corporales constituyen el mecanismo que le obliga a tomar conciencia de su problemática personal para encontrar su camino existencial. El cambio de actitud vital está intrínsecamente relacionado con la adquisición de un lenguaje personal. Los cambios lingüísticos y corporales se muestran gradualmente al lector en el texto narrativo, según avanza la historia, a través de una mayor complejidad — estructural y léxica - que refleja un pensamiento más elaborado, alejado de las enunciaciones triviales al inicio del proceso de su metamorfosis, de los truismes.

Los aspectos que hemos señalado demuestran que Darrieussecq comparte de lleno las preocupaciones de la literatura actual, en la que Dominique Viart (2004: 2932) subraya cuatro dimensiones esenciales: littérature critique, littérature transitive, littérature matérielle, littérature dialogique. La primera de ellas, la 'literatura crítica', descompone los códigos instaurados por la tradición novelística para organizar producciones narrativas más complejas. La 'literatura transitiva' trata los elementos novelísticos no como un puro trabajo de especulación imaginaria o abstracta sino que busca, en esos elementos o alrededor de ellos, huellas, documentos o signos para su interpretación. La tercera dimensión, la 'literatura material', articula esos elementos materiales con los cuales, y a propósito de los cuales, escribir para confrontarlos con los medios que le ofrece el lenguaje e impregnarse así de contenido como materialización del sentido. Y, por último, la 'literatura dialógica' que considera que esas producciones no son fruto únicamente del imaginario, sino que articulan procesos interrogativos que conducen al lector al confín entre imaginación y reflexión. Creemos que Truismes reúne estas dimensiones.

La obra de Marie Darrieussecq utiliza el código mítico de la metamorfosis y lo altera ya que la evolución se realiza de forma paulatina y no se fija definitivamente en una forma estable. El cambio físico responde a la vacilación psíquica, sus dudas se materializan corporalmente de forma fluctuante y el lenguaje manifiesta ese cuestionamiento intelectual. Los aspectos de la vida femenina son expuestos con todas sus implicaciones - personales, profesionales y sociales - desde el periodo inicial de acción mimética siguiendo los dictados del entorno cercano hasta la toma de conciencia, describiendo los procesos introspectivos que acompañan la mudanza corporal. El cuerpo no renunciará a seguir siendo una fuente de análisis y esta dimensión corporal impide al personaje doblegarse al canon social femenino.

El profesor Bruno Blanckeman revisa la relación existente entre la creación novelística actual y la tradición literaria y asegura que (2002: 13): "Entre la fiction d'hier et celle d'aujourd'hui la relation de modernité ne relève pas de l'interdit mais de l'interface". Esta frase señala, a nuestro parecer, cómo las distintas teorías de la ficción y las diversas representaciones del imaginario, superpuestas de siglo en siglo, se combinan de forma más dúctil e inestable en la actualidad. Este investigador considera además que la trayectoria narrativa del pasado no se contradice con la actual sino que constituye el motor que abre nuevas vías al relato. De esta manera, la novela contemporánea, con la tradición como bagaje, se enfrenta a los fenómenos sociales y a las realidades multiformes del mundo actual para encontrar nuevas líneas de fuga creativas. 
El mito inscribe la novela de Darrieussecq en la tradición y enriquece el relato cargando el texto de connotaciones que invitan a reflexionar, a pesar de parecer una mera fábula humorística. Truismes se vincula estrechamente con las llamadas 'ficciones transgresivas' (Berthelot, 2004: 349), modelo narrativo que se sitúa en el límite entre dos ámbitos bien diferenciados: la llamada literatura 'psicorrealista' y la literatura fantástica o de ciencia-ficción. Entre las transgresiones descritas ${ }^{3}$, Francis Berthelot cita justamente la contravención de las leyes científicas y de los mitos. La metamorfosis de mujer en cerda quebranta la ley científica dado que un organismo no se transforma de manera arbitraria en otro, la mutación en esta femme-truie responde a los vaivenes emocionales suscitados por los acontecimientos. El personaje vulnera asimismo el modelo clásico de metamorfosis ya que obedece a un efecto mágico o a un castigo de los dioses en la tradición mítica, pero, en este relato, no son provocados por ninguna fuerza externa sino que surgen de la psiquis del individuo.

La evolución del personaje se acerca más a una autorrealización personal en un sentido iniciático. El desacato del mito constituye un poderoso elemento de transgresión de la realidad por tratarse de un elemento anclado en el inconsciente, en la medida en la que arroja la luz de lo mágico, de lo sagrado sobre el mundo tangible. Por medio de su introducción, se puede incluir un tipo de supranaturaleza en la narración. Berthelot revisa numerosas obras de los últimos veinte años en las que se incluyen diferentes tipos de mitos, cristianos y paganos, hasta concluir que:

Dans tous ces ouvrages, à partir d'une relecture des religions et des mythes, la surnature fait son apparition dans le récit, transgressant à intervalles réguliers le cadre réaliste qui avait pu être posé au départ, pour entraîner le lecteur vers un ailleurs de l'âme, où ce qui lui est conté est à la fois affabulation patente et pure vérité (Berthelot, 2007: 353).

La fábula animal lleva al lector a una irrealidad aparente en la que se lee con claridad la vida contemporánea de una mujer. En una entrevista de la escritora con J.M. Terrasse sobre la génesis de sus obras, esta afirma que la idea de cambio de mujer en animal le pareció descabellada al principio; pero, tras reflexionar sobre las ficciones que consideraba particularmente interesantes ${ }^{4}$, pensó que una enfermedad le proporcionaba un tempo narrativo perfecto para ella. Darrieussecq confirma:

qu'il était très simple, au fond, de suivre cette 'maladie de la truie' dans un corps de femme et que je pouvais très concrètement décrire des symptômes, la peau qui se transforme, les poils qui poussent et le nez qui grandit (Terrasse, 2007: 257).

Por tanto, optó por emplear esa transformación disparatada para reflejar el sufrimiento físico por el que la protagonista atraviesa al doblegarse a la exigencia

\footnotetext{
${ }^{3}$ Reagrupa las narraciones transgresivas en cinco (349-357): la réalité qui dérape, la violation des lois scientifiques, mythes et surnature, tours et détours de la représentation y la création d'un monde.

${ }^{4}$ Concretamente, alude a las obras de Hervé Guibert.
} 
social, necesaria para poder mantener su puesto de trabajo. La fluctuación en la metamorfosis le sirve también para revelar el malestar psíquico causado por la inestabilidad laboral derivada de su sexo. Es decir, el sufrimiento se inscribe en su cuerpo y lo soporta como necesario e inevitable, aceptándolo sumisamente en un principio para convertirse en la hacedora de su porvenir; la narración refleja las incidencias del despertar de esa conciencia femenina.

Las interpretaciones de esta fábula han sido variadas. Algunos han visto en esa metamorfosis a la mujer escritora y su necesaria sumisión a los dictámenes editoriales. Otros han visto una sátira de la extrema derecha, más particularmente de J.-M. Le Pen que estaba muy presente en la sociedad francesa en los años de redacción de la novela (Terrasse, 2007: 258; Lantelme, 2008: 60-61). Para la autora, el objeto de su libro está claro: se trata de una mujer alienada, absolutamente inconsciente de su realidad existencial que se prostituye a las órdenes del proxeneta, el jefe de la perfumería donde trabaja. En ese momento será su cuerpo el que le facilite las claves de lo que le está ocurriendo. A través de esa metamorfosis corporal, el personaje llegará a asumir la realidad. El proceso de transformación expone la evolución hacia la consciencia de su realidad, asumiendo el gobierno de su vida. La novelista lo expone así:

Et tout à coup, son corps lui dit "tu es une personne", son corps va se transformer en monstre, et un monstre, c'est une chose qui n'a jamais eu lieu. Un monstre, c'est donc une créature qui n'a jamais pu être codifiée par la société. Les truismes, c'est-à-dire les clichés, les lieux communs n'ont pas pu recouvrir ce corps monstrueux. Or c'est une femme totalement exploitée qui, n'ayant aucune culture politique, intellectuelle, etc. n'a pas de mots. Elle ne peut utiliser que des truismes, que des clichés. Comme son corps lui dit « il t'arrive quelque chose à toi, et à toi d'une façon unique », elle est obligée de se mettre à penser pour la première fois de sa vie (Terrasse, 2007: 258).

En este punto, nos encontramos con la doble lectura de la novela cuyo título posee una ambivalencia en cuanto que la palabra francesa, truie, alude a la hembra del cerdo y, por otro lado, truisme, significa una verdad que no necesita ser enunciada por ser demasiado evidente. A este respecto, debemos observar que la traducción española 'marranadas' pierde esa segunda connotación de la palabra francesa.

En esta metamorfosis la truie no se encuentra sola ya que su pareja sentimental se transforma también en hombre-lobo. De alguna forma, la escritora trata de mantener esa doble lectura no solo individual de la mujer-cerda, sino también quiere recorrer la dimensión colectiva revisando el entorno en esa fluctuación entre sociedad humana/sociedad animal, entroncando así con toda una tradición de literatura satírica que emplea esta alegoría como reflejo de la sociedad humana. El componente social que parecía alejado de la novela desde la época estructuralista aunque no sea del todo cierto como demuestra con numerosos ejemplos Jochen Mecke (2005: 47) ${ }^{5}$ - reaparece en la novela contemporánea para tratar de mostrar

\footnotetext{
${ }^{5}$ Jochen Mecke señala como ejemplos las novelas de Claude Simon marcadas por la guerra o la
} 
la realidad circundante, pero bien es verdad que lo hace de una forma diferente. Tras el estudio de un corpus de ensayos publicados sobre la ficción y la realidad en la novela, Mecke (2005: 49) concluye que: "Donc, si nous parlons du retour du social, il s'agit plutôt d'une certaine manière nouvelle de se référer au monde social, de placer l'individu dans le monde qui l'entoure". Si el referente social parece evidente en la novelística actual, sin embargo resulta difícil encontrar una novela que declare abiertamente su intención de ilustrar una realidad social particular. El lector debe buscar esta realidad en el interior de las historias contadas, en esas vetas de vida que se le ofrecen entre líneas.

En las novelas escritas por mujeres en las que se observa la existencia de un malestar íntimo, difícil de explicar o de comprender, surgido de la desviación de la norma, se hace aún más evidente la necesaria lectura entre los pliegues del relato (Bricco, 2005: 260). En estos relatos son los propios personajes femeninos los que cuentan sus vidas, insignificantes a primera vista, pero cargadas de desdicha a la que parecen resignados. En Truismes, la reacción corporal de mutación en un cuerpo animal produce el despertar de esa mujer, su animalidad hace reaccionar a su cerebro.

\section{Cuerpo, identidad e inserción social en Truismes}

En la producción literaria francesa asistimos desde hace unas décadas a lo que se conoce como pensée-corps que incluye el cuerpo como parte constituyente de la narración e inseparable de la palabra que manifiesta el pensamiento femenino. Recordemos los trabajos de Hélène Cixous o de Chantal Chawaf en esa trayectoria. La profesora Metka Zupan subraya la preeminencia del cuerpo en la creación literaria francófona:

Quelles que soient les raisons qui incitent un bon nombre d'écrivaines contemporaines à inscrire leur littérature dans leur énergie vitale, il reste que l'insistance sur le corps comme partie intégrante du cheminement intérieur qu'est la littérature ne peut être considérée comme une mode passagère. Bien que d'autres sujets de prédilection soient en principe venus déloger le thème, la présence du corps, après les années quatre-vingt, par exemple au Québec, il semble que la nécessité de persévérer dans cette voie se soit maintenue, au Québec et en France (Zupan, 1995: 193).

Esta tradición parte de escritoras de décadas precedentes, pero cristaliza en esta última generación de mujeres novelistas. Béatrice Didier (1981: 38) en su libro L'Écriture-femme señala ya a escritoras como Nathalie Sarraute, Marguerite Duras y, más radicalmente, a Hélène Cixous como creadoras no sólo de un estilo de escritura diferente a otras autoras de épocas anteriores sino que les reconoce el poder de haber creado "presque une autre langue". La dureza de la lengua en Truismes debe

obra de Butor que ofrece su visión de la realidad estadounidense en Mobile. 
resaltarse; la narradora, consciente del lenguaje inapropiado para su condición, pide disculpas al lector al comienzo del libro por si sus palabras pudieran importunarle (Darrieussecq, 1996: 12): "Je supplie le lecteur, le lecteur chômeur en particulier, de me pardonner ces indécentes paroles". La obra se cuenta desde una primera persona como una confesión salvadora.

La heroína vuelve la mirada hacia su pasado para retomar los recuerdos en los que aparecen los primeros síntomas de la transformación animal. El personaje percibe con claridad que los cambios coinciden con una época de su vida en la que estaba en paro y nos muestra la situación en la que se encontraba. Para obtener su contrato laboral, la femme-truie nos dice claramente (Darrieussecq, 1996: 13): "le directeur de la chaîne tenait mon sein droit dans une main, le contrat dans l'autre main"; el acoso sexual, pues, como mediador de su futuro. A lo largo de las entrevistas de trabajo, su piel se vuelve más turgente y su peso va aumentando, la coacción laboral se asume e integra en el cuerpo como demanda de mejora de su imagen física según el canon masculino establecido por su patrón. Su cuerpo se moldea sumisamente en función de la tarea encomendada que se efectúa sin ninguna reflexión personal.

Paralelamente, conoce al hombre que será su compañero sentimental durante esa etapa de su vida, un profesor. El encuentro tiene lugar en un Aqualand, lugar al que acude con la finalidad de encontrarse con chicas sanas, como él las denomina. Poco después del primer encuentro, conoceremos que este hombre comprueba la salud según el nivel de cultura que posee la mujer, la falta de instrucción se instaura en elemento mayor de seducción femenina. La ignorancia de la protagonista constituye su mayor atractivo amoroso y profesional; la ingenuidad constituye la razón de su contratación en una cadena de perfumerías como vendedora y masajista, tarea que encubre su verdadero oficio de prostituta, aunque esta palabra no se enuncia. La insuficiencia terminológica como síntoma y marca narrativa de la inconsciencia en la que vive. El patrón se encarga de formarla en esas tareas difíciles que más tarde reclamarán los clientes; promoción profesional y cambio fisonómico irán unidos hasta el momento en el que ella formula sus propias peticiones.

Este giro en su actitud enoja a su jefe y motiva su despido, las causas que se aducen serán las quejas de la competencia comercial por invadir su terreno laboral. Debe, pues, mantener su papel sumiso y, por tanto, la transformación animal continúa, pero los cambios corporales se perciben ya como desagradables. Simultáneamente al fracaso profesional, surge la incomprensión de su pareja quien no acepta la toma de decisiones de esta femme-truie. La desavenencia amorosa la sumirá más profundamente en el fango, símbolo de su depresión. Aparecerán las figuras redentoras, los integristas, como ella los llama, que intentan mostrarle el camino del bien, produciéndole un sentimiento de culpabilidad al presentar este fracaso como fruto del castigo divino por su vida pasada; para solucionarlo, intenta adaptarse a las demandas del entorno personal y laboral. La protagonista, en busca de una solución para el problema causado por su imagen física - ya no sólo serán sus redondeces sino que su piel tiene ciertas erupciones cutáneas y le crecen pelos a lo largo de su cuerpo-, visita a varios médicos para aliviar sus graves problemas de 'alergia' y 
recobrar la belleza anterior que le proporcione "sa dernière chance" (Darrieussecq, 1996: 49). En esta novela, la metamorfosis constituye un proceso intrínseco al crecimiento individual en el que no intervienen fuerzas mágicas o extraordinarias, pero el entorno social percibe el desarrollo personal de esta mujer como una enfermedad.

En el psicoanálisis al que somete su vida se estudiarán cuestiones clave de la problemática femenina en la sociedad contemporánea como la maternidad y el aborto, se revisan además sentimientos ambiguos de culpa frente al fracaso afectivo y se observa una sensación de bienestar inconsciente ligado a la alteración experimentada. El proceso de búsqueda de su identidad le lleva a reconocerse tal cual es y la imagen que el espejo le devuelve no le agrada; hundida literalmente en ese simbólico fango, siente necesidad de lavarse como imagen de su purificación, pero no logra su objetivo porque todas las puertas se le cierran. Su descenso a los 'infiernos' continúa y, ante la impotencia del cambio por variables que no logra controlar - ya convertida totalmente en cerda-, disfrutará revolcándose en las charcas de barro y se esconderá en las alcantarillas con la única compañía de las ratas.

En este periodo, de imprecisa duración temporal, encuentra comprensión junto a seres marginales de la sociedad como el limpiador, un emigrante 'sin papeles' que la cuida y con el que entabla una verdadera comunicación a pesar de no hablar la misma lengua. A través de este personaje y de esos lugares marginales se revisarán estamentos de la organización política. Solamente el aire fresco del exterior aliviará sus tensiones, el olor del 'campo' le atrae cada vez con mayor fuerza aunque, antes de esa retirada campestre final, tratará de buscar un nuevo trabajo en la ciudad que le causará de nuevo efectos nefastos como la cárcel. Se salvará de esta crisis por la 'infección de libros' que sufre, libros que intenta comerse pero que, tras graves problemas digestivos, comprende finalmente que debe descifrarlos para sanar. Las lecturas transforman su evolución y logra alzarse sobre sus dos patas traseras y retomar su vida, que adquiere una forma más humana, logrando huir además de la persecución del fanatismo religioso.

En tono un tanto apocalíptico se narra cómo, ante numerosos hechos de corrupción, engaños y juegos de poder estallará una guerra, que la protagonista da por hecho que los lectores conocen. El conocimiento puede proceder del mundo real pero también marca la intertextualidad, la memoria literaria de otras obras como $L a$ Peste de Camus por ejemplo; la Epidemia - aparece con mayúscula en el texto-y la hambruna, referencia a la obra Hambre de Knut Hamsum, cuya cita abre el libro'. Lógicamente, ella se esconde para protegerse y no ser devorada puesto que su carne es muy preciada.

Las últimas treinta páginas del libro son de reencuentro con el amor, con una persona de gran belleza, poseedor de fortuna, ideal de masculinidad y con la capa-

\footnotetext{
${ }^{6}$ Brunel (2002b: 198) realiza un estudio sobre los rasgos paralelos entre la obra de Darrieussecq y la de Hamsun (1858-1952), autor escandinavo naturalista que acabo su vida abrazando la causa nazi.
} 
cidad de transformarse en lobo, con él logrará cierta armonía. El lobo, como no podía ser menos, no puede acallar sus instintos agresivos y cometerá un crimen por el que será abatido por la policía. Esa agresividad del lobo contamina a su compañera, la mujer-cerda, que se convierte así en una superviviente nata que termina matando a su madre quien, a su vez, pretendía acabar con ella. A propósito de este matricidio, Darrieussecq afirma (Barraband \& Gassman, 2005: 9): "Il y a une logique narrative très forte dans le livre qui aboutit au meurtre de la mère parce que c'est la seule façon pour la narratrice d'affirmer qu'elle n'est plus de la même espèce que sa mère". Como en otros tantos relatos, la muerte de la madre es necesaria para la afirmación de la identidad de la narradora, la femme-truie rompe con una tradición de comportamiento femenino.

Finalmente, elegirá vivir en el campo entre cerdos con los que se siente mejor que en la ciudad, seguirá tomando forma humana o animal según las circunstancias, pero será fuerte y se opondrá a lo que signifique su destrucción. No se producirá una catarsis final en el sentido de purificación emocional, corporal, mental o espiritual definitiva, sino que existe la reivindicación de un proceso personal que no se adapta a ninguna regla preconcebida. El principio rector de su existencia será la supervivencia personal dentro de esta sociedad, según las normas que se ha dado a sí misma tras el proceso reflexivo y corporal sufridos; la protagonista elabora su sistema de pensamiento autónomo cuyos razonamientos no olvidan la parte emocional e instintiva.

\section{Conclusiones}

La narradora emplea un tono falsamente ingenuo para hablar de la mujer y del mundo. La vía elegida por el personaje para alcanzar un grado de felicidad es una vuelta hacia su cuerpo, aceptando su diferencia y rechazando todas las formas preconcebidas de la existencia hasta llegar a encontrar su fórmula existencial, su patrón de conducta no será exclusivamente animal ni humano sino que compartirá los dictámenes de ambas naturalezas.

La novela comienza retrocediendo al pasado, al momento tras el asesinato de la propia madre; este acto matricida le permite liberarse y poder así tomar finalmente las riendas de su propia vida. En cierta manera, la escritora construye una novela iniciática que parte de la inconsciencia de la joven que sale de la casa familiar hasta llegar a la madurez en la que, tras sus experiencias, decide apartarse de los caminos al uso y llevar una vida retirada rodeada de otros seres de su especie para encontrar su identidad femenina. Como señala Sarrey-Strack (2002: 190): “C'est tout d'abord par le corps que l'on est (que l'on naît) dans les romans de Marie Darrieussecq". El cuerpo de la narradora adquiere una dimensión simbólica como elemento per se del ser en el mundo, sobre él se van a inscribir todas las trasformaciones. Desde la alienación primera en la que la protagonista constituye un mero objeto en manos de Honoré, hasta el momento final en el que logra desviar los instintos asesinos de su compañero sentimental — dirigidos a ella- hacia el repartidor de pizzas y así 
librarse de la muerte. De él reproduce la agresividad que le permite librarse de su propia madre, como proceso de individualización del sujeto femenino.

El cuerpo es el soporte de la memoria, y será a través de él como la narradora tomará conciencia de su existencia y del mundo. El proceso de escritura resulta inseparable de su experiencia cochonne y quedará marcado por esa misma contaminación animal. El cuerpo (sexuado) del individuo, como ha señalado Bourdieu (Sarrey-Strack, 2002: 216), está profundamente anclado en una cultura que lo fabrica a la medida de las diferencias sociales percibidas entre los seres. Truismes ilustra, bajo la forma de la fábula, el simbolismo del cuerpo de la mujer ligado al terreno social y político. Desde esta perspectiva que integra los códigos individuales de la mujer-cerda, los condicionamientos sociales se revisan con humor empleando el mito greco-latino de la metamorfosis para deconstruir y mostrar los prototipos clásicos femeninos.

\section{REFERENCIAS BIBLIOGRÁFICAS}

Aron, P. et al., (2002) Le Dictionnaire du Littéraire. Paris, PUF.

Barraband M. \& X. Gassman, (2005) "Entretien avec Marie Darrieussecq" in La lettre de l'enfance et de l'adolescence. 2005/1, no 59, pp. 9-16.

Blanckeman, B., (2002) Les fictions singulières. Études sur le roman contemporain. Paris, Prétexte éditeur.

Berthelot, F., (2004) "Les fictions transgressives" in Blanckeman, B. et al. (éds.), Le roman français au tournant du XXIe siècle. Paris, Sorbonne Nouvelle.

Bricco, E., (2005) "Marginales et solitaires dans les romans de Sylvie Germain, Dominique Mainard, Marie NDiaye et Marie Redonnet" in Collomb, M. (éd.), L'empreinte du sociale dans le roman depuis 1980. Montpellier, Service des publications de l'Université Paul Valéry, pp. 259-266.

Brügger N. et al., (1993) Lyotard, les déplacements philosophiques. Bruxelles, De Boeck-Wesmael.

Brunel, P., (2002a) Où va la littérature française d'aujourd'hui. Paris, Vuibert.

Brunel, P., (2002b) Voix autres, voix hautes. Onze romans de femmes au XXe siècle. Paris, Klincksieck.

Brunel, P., (2004) Le mythe de la métamorphose. Paris, Pierre Corti.

Darrieussecq, M., (1996) Truismes. Paris, Gallimard, coll. Folio.

Darrieussecq, M., (2007) "Je est unE autre" in Olivier, A. (ed.), Ecrire l'histoire d'une vie [En línea]. Roma, Edizioni Spartaco. Disponible en: www.uri.edu/artsci/ml/durand/darrieussecq/fr/collautofiction.doc [Ultimo acceso el 20 de agosto de 2010].

Didier, B., (1981) L'écriture-femme. Paris, PUF.

Dytrt, P., (2009) "La postmodernité comme modernité interrogée" in Barraband, M. \& A. Lasserre (éds.), Synthèses. Cahiers du CERCC, no 4, pp. 79-92.

Lantelme, M., (2008) Le roman contemporain. Janus Postmoderne. Paris, L'Harmattan. 
Martín Rodríguez, A., (2002) De Aedón a Filomela. Génesis, sentido y comentario de la versión ovidiana del mito. Las Palmas de Gran Canaria, Universidad de Las Palmas.

Miller, B. \& M. Holmes, (2001) "Entretien avec M. Darrieussecq" in http://darrieussecq.arizona.edu/fr/entretien2001.html [Último acceso el 10 de abril de 2012].

Mecke, J., (2005) "Le social dans tous ses états: le cas Houellebecq" in Collomb, M. (éd.), L'empreinte du sociale dans le roman depuis 1980. Montpellier, Service des publications de l'Université Paul Valéry, pp. 47-64.

Sarrey-Strack, C., (2002) Fictions contemporaines au féminin. Paris, L'Harmattan.

Terrasse, J.-M. (2007) "Comment j'écris" in Gifford, P. \& M. Schmid (éds.), La création en acte. Devenir de la critique génétique. Amsterdam/New-York, Rodopi, pp. 253-268.

Tubert, S., (1996) "Psicoanálisis, feminismo, postmodernismo" in Foros Temáticos. Género, psicoanálisis, subjetividad [En línea]. Disponible en: http://www.psicomundo.com/foros/genero/posmo.htm [Último acceso el $20 \mathrm{de}$ marzo de 2012].

Viart, D. \& B. Vercier (dir.), (2008) La littérature française au présent. Paris, Bordas.

Viart, D. et al., (2004) Le roman français aujourd'hui. Transformations, perceptions mythologies. Paris, Prétexte éditeur.

Zupan, M., (1995) "Corps intégré, corps sacralisé dans la littérature contemporaine des femmes" in Religiologiques. №12, pp. 191-206. 